\title{
Teacher-reported emotional and behavioural problems and ethnic background associated with children's psychosocial care use: a longitudinal population-based study
}

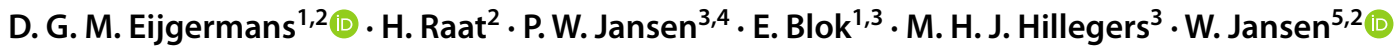

Received: 7 May 2021 / Accepted: 22 December 2021

(C) The Author(s) 2022

\begin{abstract}
Approximately, $15 \%$ of children in Western countries suffer from emotional and behavioural problems. However, not all children receive the psychosocial care they need, especially children with a non-Western background experience an unmet need for care. This might be because parents of non-Western children report a lower need for care than parents of Western children, unrelated to the actual need. This study examined the association between teacher-reported problems and psychosocial care use, independent of mother-reported problems. Further, the role of ethnic background in this association was investigated. The study sample of 9-year-old children was retrieved from the Generation R Study $(N=3084)$, a prospective, population-based cohort of children born in Rotterdam, the Netherlands. Teacher- and mother-reported problems were measured via questionnaire when the children were 6/7 years old. Psychosocial care use was mother-reported at the research centre when children were 9 years old (8.1\%). Hierarchical logistic regressions showed significant positive associations between teacher-reported total, externalising and internalising problems and later psychosocial care use. These associations were independent of mother-reported problems. Children with a non-Western background used less care, but ethnic background did not moderate the association between teacher-reported problems and care use. Our findings suggest that teachers might have an important role, next to parents, in the identification of problems and children's access to care. This may be particularly important for non-Western children, as they use less psychosocial care than Western children, despite other research showing that they generally display higher levels of problems. Directions for future research and implications are discussed.
\end{abstract}

Keywords Psychosocial support systems · Psychosocial intervention - Social determinants of health $\cdot$ Health services needs and demand $\cdot$ School teachers

Approximately, 15\% of the children in Western countries suffer from emotional and behavioural problems [1-4]. The

W. Jansen

w.jansen@ rotterdam.nl

1 The Generation R Study Group, Erasmus MC, University Medical Centre, Rotterdam, The Netherlands

2 Department of Public Health, Erasmus MC, University Medical Centre, Rotterdam, The Netherlands

3 Department of Child and Adolescent Psychiatry/Psychology, Erasmus MC, University Medical Centre, Rotterdam, The Netherlands

4 Department of Psychology, Education and Child Studies, Erasmus University Rotterdam, Rotterdam, The Netherlands

5 Department of Social Development, City of Rotterdam, P. O. Box 70032, 3000 LP Rotterdam, The Netherlands prevalence of these problems in Western countries seems to be higher among children with a non-Western background than children with a Western background [5, 6]. It is, therefore, worrying that children with a non-Western background receive, on average, less psychosocial care than their Western peers [7-10]. A possible explanation of the lower psychosocial care use among these children is the perceived need for care. Several studies have shown that, regardless of the mental problems, the perceived need for psychosocial care is lower in non-Western people than in Western people, including children [11, 12].

Apparently, children's need for care is not always interpreted in the same way by parents, while the recognition of problems by parents is an important step in the pathway to psychosocial care [13]. Hence, other important adults, e.g. teachers, may play an essential role in recognising children's emotional and behavioural problems $[14,15]$. Teachers 
might have a different perception of the children's need for psychosocial care than parents, because they view children's emotional development and behaviour in a different setting and in the context of peers. As such, teachers may support children and their families in the pathway to care, which may ultimately help to attenuate the ethnic background differences in children's psychosocial care use. However, only little research has been performed on the association between teacher-reported emotional and behavioural problems and children's psychosocial care use. It is important to understand - yet not studied before- whether this association depends on the parent-reported problems, because the differences in care use between ethnic groups are partly explained by the differences in parents' recognition of problems $[11,12]$.

Three population-based, longitudinal studies on this subject show contradicting findings. Raven et al. [16] found that teacher-reported internalising problems at 11 years old were associated with increased care use in the age range of 11-13 years, but that teacher-reported internalising problems later in adolescence and externalising problems overall were not associated. Sourander et al. [17] identified the teacher's reported need for referral at 8 years old as a determinant for psychosocial care use at 16 years old. However, both studies did not investigate the role of ethnic background in the associations. The third study, by Erath et al. [9], did include ethnic background and focussed solely on externalising problems. In this study, teacher-reported externalising problems during kindergarten were associated with increased care use. This study showed that children with a European-American background used more psychosocial care than children with an African-American background. However, no interaction between ethnic background and externalising problems was found.

It has been shown that ethnic background is a moderator in the association between parent-reported problems and psychosocial care use; children were more likely to use care when they had a Western background compared to a nonWestern background $[9,18,19]$. However, whether the association between teacher-reported emotional and behavioural problems and psychosocial care use is moderated by ethnic background is unclear since the literature is scarce and inconclusive. This study aims to investigate whether teacherreported emotional and behavioural problems are associated with children's psychosocial care use, and whether this association is independent of parent-reported emotional and behavioural problems. Subsequently, this study aims to investigate whether children's ethnic background moderates the possible association between teacher-reported emotional and behavioural problems and children's psychosocial care use. This study includes teacher-reported total, externalising and internalising problems. By studying these aims, we will provide insight into the teachers' possible role in early detection of the need for care in young children, also for children with a non-Western background. Furthermore, this study could contribute to improve prevention strategies and facilitate early intervention [20].

\section{Methods}

\section{Data collection}

We used data from the Generation R Study, a prospective, population-based cohort study of children born in Rotterdam, the Netherlands, which has been described elsewhere [21]. In this cohort, 9749 children and their parents are followed from foetal life onwards. In total, 5862 participants visited the research centre for the measurement wave at 9 years between 2011 and 2014. Children who dropped out of the study were more likely to be boys, have a non-Western background, and have parents with a low educational level compared to the remaining sample [21]. Children with complete data on psychosocial care use and teacherreported problems were included in the current study. Thus, participants were excluded because of missing data on psychosocial care use $(N=363)$ or teacher reports $(N=2415)$, resulting in a sample of 3084 participants. The Medical Ethics Review Board of the Erasmus Medical Centre approved the study protocols. All parents provided written informed consent.

\section{Measures}

Psychosocial care. Parents were asked about psychosocial care use of their child at 9 years old. The question at the research centre was: 'Has your child in the past twelve months been examined or treated for any mental health problem by a professional?' Eight different types of psychosocial care were distinguished, i.e. five forms of specialised mental health care, social work, preventive youth health care, and the general practitioner. Visiting only preventive youth health care or the general practitioner was recoded into using no care $(16 \%)$ because they mainly provide preventive care or refer, but do not offer treatment for emotional and behavioural problems. The remaining six care providers were combined to 'psychosocial care use in the past year'.

\section{Teacher-reported emotional and behavioural problems}

The Teacher Report Form (TRF), 6-18 years, was used to measure the children's emotional and behavioural problems [22]. The TRF was filled out by the teacher of the participants when the children were on average 6.7 years old and consists of 112 items scored on a three-point scale. The TRF shows good validity and reliability [22]. The crude TRF 
scores were adjusted for residual differences regarding age and sex. Hereafter, the 83rd percentile cutoff points, based on the total Generation R sample, were used to determine the total problem score's borderline or clinical range. Children scoring on or above this cutoff were classified as having emotional and behavioural problems according to the teacher. Since we have a relatively healthy sample, we will describe this as 'having problems above the 83rd percentile' instead of 'having borderline/clinical problems'. The same procedure was followed for the internalising and externalising problems scale.

\section{Ethnic background}

Ethnic background of the child was measured via a questionnaire when the children were 6 years old. Children were classified as having Western background when both parents were born in a Western country [23]. If one or both parents were born in a non-Western country, the child was classified as having a non-Western background.

\section{Covariates}

To test whether the associations were independent of potential confounding factors, we adjusted for sex (boy vs girl), educational level of both parents (high vs mid-high vs midlow vs low), and family situation (two-parent family vs one-parent family). These sociodemographic factors were also accounted for in the previously described populationbased, longitudinal studies on this topic $[9,16,17]$. Additionally, we adjusted for age at the outcome measurement, based on the day of visiting our research centre. Furthermore, to investigate the independent association of teacherreported problems, we adjusted for mothers' parent-reported problems. The mother-reported emotional and behavioural problems were obtained via de Child Behavior Checklist (CBCL/1 $\left.1 \frac{1}{2}-5\right)$ when the children were on average 6.0 years old. The CBCL consists of 99 items [24]. The same residual and cutoff procedures as for the TRF were followed.

\section{Analyses}

Missing values on the covariates were imputed 20 times using multiple imputation methods. A significance level of $p<0.05$ was maintained in all analyses. Analyses were performed using IBM SPSS Statistics 25.

Descriptive statistics were used to summarise the characteristics of the study population. The association between teacher-reported emotional and behavioural problems, ethnic background and psychosocial care use at 9 years old was studied using hierarchical logistic regression analyses. The variables were entered as follows: teacher-reported problems and ethnic background were studied in univariate analyses.
In the next step, Model 1, teacher-reported emotional and behavioural problems and ethnic background were entered together. Model 2 consists of the Model 1, and age at visit of the research centre (at time of outcome measurement), sex, educational level of mother and father, and family situation. Model 3 consists of Model 2 and mother-reported emotional and behavioural problems. The hierarchical models were applied three times: once with the TRF total problems score, once with the TRF externalising problems score and once with the TRF internalising problems score. To study the possible moderating role of ethnic background, the interaction term between teacher-reported problems and ethnic background was added to Model 3.

\section{Additional and complete case analyses}

As additional analysis, the moderating role of motherreported problems was studied by adding the interaction term between teacher- and mother-reported problems to Model 3. The association between teacher-reported problems and psychosocial care use might differ for children whose mothers do and do not report emotional and behavioural problems, as parents most often seek psychosocial care for their children [13]. A complete case analyses was performed to investigate whether the imputation influenced the results.

\section{Results}

Children in the sample were on average 9.8 (SD 0.3) years old, the majority (68.0\%) had a Western background, and almost half (49.4\%) were boys. More sociodemographic characteristics and the percentages of emotional and behavioural problems above the 83rd percentile are described in Table 1. Psychosocial care was used in the past year by $8.1 \%$ of the children. Among those children who used psychosocial care in the past 12 months (age nine years; $N=250$ ), $10 \%$ had emotional and behavioural problems above the 83rd percentile at 6 years old according to both the teacher and the mother (see Fig. 1). A higher percentage only had problems according to either the mother $(16 \%)$ or the teacher (22\%). More than half of the children that used care $(52 \%)$ had no problems at 6 years old according to the mother and teacher. A similar pattern was present among the children that did not use care in the past year: at age 6 years, a small percentage had problems above the 83rd percentile according to the teacher as well as the mother (3\%), and a larger percentage according to either the mother $(10 \%)$ or the teacher $(11 \%)$. 
Table 1 Characteristics of the total study sample $(N=3084)$

\begin{tabular}{|c|c|c|c|}
\hline Data before imputation & $N(\%)$ & Miss. $\%$ & $\begin{array}{l}\text { Percent of group that used } \\
\text { psychosocial care in the past } \\
\text { year }\end{array}$ \\
\hline Psychosocial care use in the last 12 months & $250(8.1)$ & 0.0 & 100 \\
\hline Age at visit to research centre (in years) & $9.78( \pm .33)$ & & N.A \\
\hline \multicolumn{4}{|l|}{ Ethnic background } \\
\hline Western & $1952(68.0)$ & 6.9 & 9.0 \\
\hline Non-Western & $920(32.0)$ & & 6.4 \\
\hline \multicolumn{4}{|l|}{ Sex } \\
\hline Boy & $1523(49.4)$ & 0.0 & 10.1 \\
\hline Girl & $1561(50.6)$ & & 6.1 \\
\hline \multicolumn{4}{|l|}{ Educational level mother } \\
\hline Low & $423(14.8)$ & 7.2 & 5.7 \\
\hline Mid-low & $895(31.3)$ & & 9.8 \\
\hline Mid-high & $767(26.8)$ & & 9.8 \\
\hline High & $777(27.1)$ & & 6.3 \\
\hline \multicolumn{4}{|l|}{ Educational level father } \\
\hline Low & $443(17.1)$ & 16.0 & 8.4 \\
\hline Mid-low & $698(26.9)$ & & 9.7 \\
\hline Mid-high & $608(23.5)$ & & 8.6 \\
\hline High & $841(32.5)$ & & 7.1 \\
\hline \multicolumn{4}{|l|}{ Family situation } \\
\hline Two-parent family & $2319(86.8)$ & 13.3 & 8.2 \\
\hline One-parent family & $354(13.2)$ & & 8.8 \\
\hline \multicolumn{4}{|c|}{ Teacher-reported emotional/behavioural problems above the $83 \mathrm{rd}$ percentile } \\
\hline \multicolumn{4}{|l|}{ Total problem score } \\
\hline Yes & $468(15.2)$ & 0.0 & 17.1 \\
\hline No & $2616(84.8)$ & & 6.5 \\
\hline \multicolumn{4}{|l|}{ Externalising score } \\
\hline Yes & $476(15.4)$ & 0.0 & 19.3 \\
\hline No & $2608(84.6)$ & & 6.1 \\
\hline \multicolumn{4}{|l|}{ Internalising score } \\
\hline Yes & $514(16.7)$ & 0.0 & 12.5 \\
\hline No & $2570(83.3)$ & & 7.2 \\
\hline \multicolumn{4}{|c|}{ Mother-reported emotional/behavioural problems above the 83 rd percentile } \\
\hline \multicolumn{4}{|l|}{ Total problem score } \\
\hline Yes & $406(15.4)$ & 14.3 & 15.8 \\
\hline No & $2237(84.6)$ & & 7.1 \\
\hline
\end{tabular}

Percentages are valid percentages and, therefore, add up to $100 \%$ without the missing values

Miss. missingness within the variable

The numbers in Italics represent the percentage of missing values withinthe variable

\section{Teacher-reported emotional and behavioural problems and psychosocial care use}

The presence of teacher-reported total, externalising and internalising problems above the 83 rd percentile were all associated with psychosocial care use in 9-year-old in the univariate analyses $(p<0.05$, see Table 2$)$. Children with total problems according to the teacher were more likely to receive care when adjusted for sociodemographic factors [odds ratio (OR): 3.06; 95\% confidence interval (95\% CI): 2.26-4.15]. Children with teacher-reported externalising problems were also more likely to receive care (OR 3.84; 95\% CI:2.86-5.17). The association for children with teacher-reported internalising problems showed a lower—but still significant—odds ratio (OR 1.86; 95\% CI $1.37-2.53)$. 
Fig. 1 Teacher- and parentreported problems at 6 years old, stratified for children that do and do not use psychosocial care

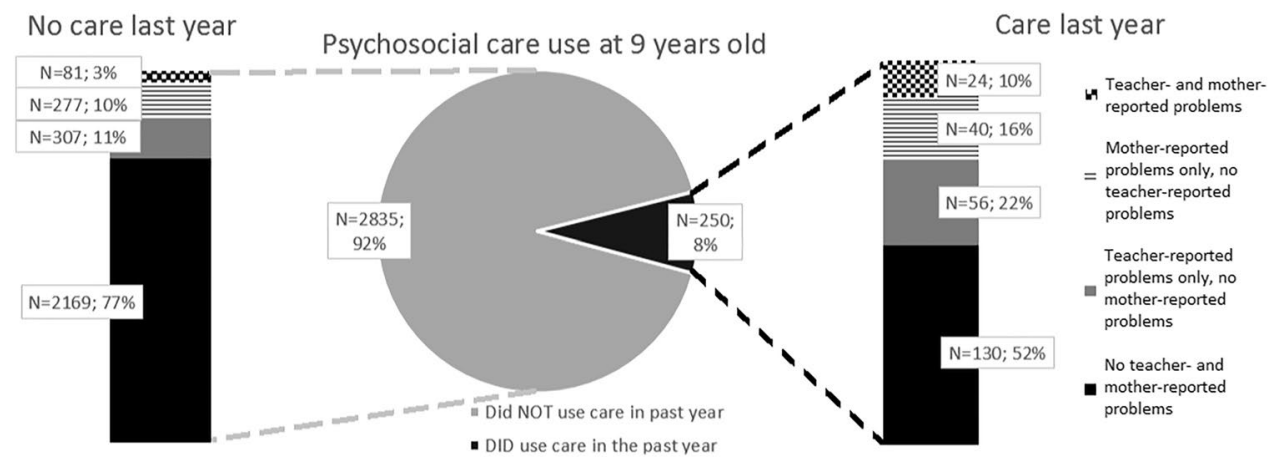

\section{The association independent of mother-reported problems}

Mother-reported problems were added in Model 3. This resulted in attenuated, but still significant, associations between the teacher-reported problems and care use, i.e. for total problems (OR 2.10; 95\% CI 1.51-2.93), externalising problems (OR 2.06; 95\% CI 1.47-2.87), and internalising problems (OR 2.25; 95\% CI 1.63-3.11). Mother-reported total problems above the 83 rd percentile were also significantly associated with psychosocial care use, independently of teacher-reported problems (see Model 3 of Table 2).

\section{Children's ethnic background in this association}

Children with a non-Western background were less likely to use psychosocial care in all models compared to children with a Western background (see Table 2). The association

Table 2 Multivariable hierarchical logistic regression with presence of teacher-reported emotional and behavioural problems at 6 years old, ethnic background and psychosocial care use at 9 years old $(N=3084)$

\begin{tabular}{|c|c|c|c|c|}
\hline & $\begin{array}{l}\text { Univariate analyses } \\
\text { OR }(95 \% \mathrm{CI})\end{array}$ & $\begin{array}{l}\text { Model } 1 \\
\text { OR }(95 \% \text { CI })\end{array}$ & $\begin{array}{l}\text { Model } 2 \\
\text { OR (95\% CI) }\end{array}$ & $\begin{array}{l}\text { Model } 3 \\
\text { OR (95\% CI) }\end{array}$ \\
\hline \multicolumn{5}{|l|}{ Overall problem level } \\
\hline \multicolumn{5}{|l|}{ Teacher-reported problems } \\
\hline Presence of total problems ${ }^{\mathrm{a}}$ & $2.97(2.23-3.95)$ & $3.23(2.41-4.33)$ & $3.06(2.26-4.15)$ & $2.83(2.09-3.86)$ \\
\hline \multicolumn{5}{|l|}{ Ethnic background } \\
\hline Western (ref.) & 1.00 & 1.00 & 1.00 & 1.00 \\
\hline Non-Western & $.69(.51-.94)$ & $.60(.44-.82)$ & $.60(.43-.85)$ & $.58(.41-.82)$ \\
\hline Mother-reported total problems & $2.41(1.76-3.31)$ & - & - & $2.10(1.51-2.93)$ \\
\hline \multicolumn{5}{|l|}{ Externalising problems } \\
\hline \multicolumn{5}{|l|}{ TRF } \\
\hline Presence of externalising problems ${ }^{\mathrm{a}}$ & $3.72(2.81-4.91)$ & $3.95(2.98-5.24)$ & $3.84(2.86-5.17)$ & $3.59(2.66-4.85)$ \\
\hline \multicolumn{5}{|l|}{ Ethnic background } \\
\hline Western (ref.) & 1.00 & 1.00 & 1.00 & 1.00 \\
\hline Non-Western & $.69(.51-.94)$ & $.60(.44-.83)$ & $.63(.44-.88)$ & $.61(.43-.86)$ \\
\hline Mother-reported total problems & $2.41(1.76-3.31)$ & - & - & $2.06(1.47-2.87)$ \\
\hline \multicolumn{5}{|l|}{ Internalising problems } \\
\hline \multicolumn{5}{|l|}{ TRF } \\
\hline Presence of internalising problems ${ }^{\mathrm{a}}$ & $1.82(1.35-2.46)$ & $1.91(1.41-2.59)$ & $1.86(1.37-2.53)$ & $1.75(1.28-2.39)$ \\
\hline \multicolumn{5}{|l|}{ Ethnic background } \\
\hline Western (ref.) & 1.00 & 1.00 & 1.00 & 1.00 \\
\hline Non-Western & $.69(.51-.94)$ & $.66(.48-.89)$ & $.62(.44-.87)$ & $.60(.42-.84)$ \\
\hline Mother-reported total problems & $2.41(1.76-3.31)$ & - & - & $2.25(1.63-3.11)$ \\
\hline
\end{tabular}

Bold: represents $p \leq 0.05$

OR odds ratio for psychosocial care use at age 9 years, 95\% CI 95\% confidence interval, TRF Teacher Report Form

${ }^{a}$ Teacher-reported total problems above the 83rd percentile. Model 1: ethnic background, TRF total problem score. Model 2: Model 1+age at visit research centre (outcome), sex, educational level mother and father, family situation. Model 3: Model 2+ mother-reported emotional and behavioural problems 
between children's ethnic background and psychosocial care use remained stable and significant after adjusting for all covariates in Model 3, i.e. having a non-Western background was associated with less care use (e.g. OR $0.58 ; 95 \%$ CI $0.41-0.82$ in the analysis with total problems). None of the interaction terms between teacher-reported problems (total, externalising and internalising problems) and ethnic background showed a significant $p$ value in Model 3 (all $p>0.05$, see Supplement SI).

\section{Additional and complete case analyses}

In the additional analyses, we tested whether the association between teacher-reported problems and psychosocial care use was different for children of mothers who do and do not report problems by adding interaction terms. None of the interactions between the teacher-reported total, externalising and internalising problems and mother-reported total problems were significant (all $p>0.05$, see Supplement Table SI).

The complete case analyses showed that all odds ratios were in the same direction as in Model 3 of Table 2 (see Supplement Table SII). On average, the associations were slightly stronger for the total (OR 3.52; 95\% CI 2.50-4.96), externalising (OR 3.84; 95\% CI 2.74-5.38) and internalising problem level (OR 2.04; 95\% CI 1.45-2.88), compared to the analyses on the imputed data. The association between children's ethnic background and psychosocial care use remained stable compared to the imputed data, i.e. having a non-Western background in the analysis with total problems (OR 0.58 ; 95\% CI 0.40-0.85), with externalising problems (OR: 0.63 ; 95\% CI 0.43-0.92), and with internalising problems (OR 0.63; 95\% CI 0.43-0.92). None of the interactions was significant in the complete case analyses $(p>0.05$, results not shown).

\section{Discussion}

Our study's main findings are that teacher-reported total, externalising and internalising problems above the 83rd percentile (i.e. representing borderline/clinical problems) at 6 years old were associated with psychosocial care use at 9 years old. This association remained significant after adjusting for mother-reported total problems and was not moderated by ethnic background of the child. This association was also not significantly different for mothers that did and did not report emotional and behavioural problems of their child as we found no interaction effect between teacherand mother-reported problems. Further, children with a nonWestern background used less psychosocial care compared to children with a Western background, unrelated to their problem level.
Our study findings are in line with previous studies on differences in psychosocial care use between children with a Western and non-Western background [7-10]. To our knowledge, the study of Erath et al. [9] is the only study investigating the potential moderation by ethnic background in the association between teacher-reported problems and care use. They only investigated teacher-reported externalising problems. They, too, did not find a moderating role for ethnic background, while care use was significantly lower among children with a non-Western background. An explanation introduced by Ivert et al. [25] pertains to differences in the pathways to care. They show that the referral to psychiatric clinics in Swedish (non-migrant) children is most often initiated by their parents, while in migrant children with a South American or Asian background, referrals were more likely to be initiated by school or the health-care sector. These different pathways might be explained by acculturation issues that parents with a migrant origin have to deal with, e.g. language barriers and the knowledge of the health care system $[26,27]$. Research shows that those experiencing the most issues are the least likely to receive mental health care [26, $28]$. These issues differ according to country of origin and decrease by time of residence $[28,29]$. These acculturation issues might explain the differences in the pathways to care and why ethnic background does moderate the association between parent-reported problems and mental health care use $[9,18,19]$, but not the association between teacherreported problems and care use.

Other explanations on the relative lower care use by children with a non-Western background are present in the literature as well. Nanninga et al. [30] found that non-Dutch parents prefer to solve the psychosocial problems of their child themselves and that they have less confidence in the treatment and therapists than Dutch parents. Flink et al. [31] described how children with a Turkish and Moroccan background in the Netherlands fear the potential negative reactions from parents and friends regarding their psychosocial care use, including disappointment, worrying, or shame. These negative attitudes towards care and fear of stigma are related to reduced help-seeking activities [32]. Johnson et al. [33] showed that parents with minority backgrounds in the USA experience greater barriers to mental health care, e.g. transportation to the care facility, and also rate the quality of care lower.

Our study findings on the associations of the teacherreported total, externalising and internalising problems at 6 years old with psychosocial care use at 9 years old are in line with previous studies on this association $[9,17]$. The current study adds to the findings of previous studies by its focus on psychosocial care use in childhood, while the other studies focus on adolescence. This might also explain the differences with the study by Raven et al. [16], who only found an association for teacher-reported internalising problems 
in early adolescence, but not for internalising problems in later adolescence or externalising problems. Additionally, the current study shows that the association of teacherreported problems and psychosocial care use is independent of mother-reported problems. This implies that the recognition of problems by the teacher can be of added value next to the recognition of problems by parents. To our knowledge, no other studies adjusted for parent-reported problems.

In our study sample, psychosocial care in the past year was received by $8.1 \%$ of our 9 -year-old sample. This is somewhat lower than the registered care use of $10 \%$ in 2015 in the Netherlands [34], which can probably be explained by our relatively healthy study sample. Remarkably, more than half of the children (52\%) that received care in the past year did not score above the 83 rd percentile on emotional and behavioural problems at 6 years old, according to the teachers and mothers. Only $10 \%$ of the children who received care did have a score above the 83rd percentile according to the teacher as well as the mother. Of the children that used care, $22 \%$ had only teacher-reported problems and no mother-reported problems. In more detail, for children with a Western background, this percentage was $19 \%$, and for children with a non-Western background, this percentage was 33\% (data not shown). This implies that teachers may especially play an important role in identifying emotional and behavioural problems by children with a non-Western background. Additionally, a recent study—on the association between mental disorders and teacher concerns about children's mental health in British children-also concludes that teachers can play a valuable role in referral decisions as teacher concerns proved to be moderately predictive of disorders [35]. This provides opportunities as currently in the Netherlands teachers formally have no active role in the screening on mental health problems.

The discrepancy between the teacher-reported emotional and behavioural problems at 6 years old and psychosocial care use at 9 years old is considerable. On the one hand, only a small percentage of the children (17\%, see Table 1$)$ with teacher-reported problems above the 83 rd percentile does receive care. On the other hand, the majority of the children receiving care did not have the highest teacherreported problem scores (68\%, see Fig. 1). It is possible that emotional and behavioural problems in children reported at age 6 diminished or increased between the age of 6 and 9 . However, it is not likely that these changes explain the entire discrepancy [36]. Further, children with high problem levels might already have been treated for their problems before the age of 9. Again, this is also not likely to be the full explanation, as only $13.7 \%$ of the children with teacher-reported problems did receive earlier care (data not shown). Another explanation why children without high problem levels use care might be that the TRF and CBCL do not fully cover the reasons for psychosocial care use by children. However, the most likely explanation is that, in practice, not all children with the most problems and highest needs receive psychosocial care, while conversely a substantial number of children who receive care may not have the highest needs [37].

\section{Strengths and limitations}

This study has several strengths. First of all, we studied a young sample of children. This age category has not often been studied since most studies so far focussed on adolescents [38]. Secondly, we studied a general population to increase the generalisability of our findings and to be able to inform public health policies better. Furthermore, we used a longitudinal design in a large cohort which strengthens the findings. Using the longitudinal design increases the likelihood that teacher-reported problems were present before the care was received. Lastly, we adjusted for mother-reported problems. Recognition of problems by parents often is the first step in the help-seeking process. Because we adjusted for mother-reported problems, our results show the added value of the teachers' problem recognition.

This study also has some limitations. First of all, teacherreported problems might be biased by the rest of the school class [39]. Teacher-reported problems can be influenced positively and negatively by school and class-related factors. Secondly, the teacher- and mother-reported problems are not filled out at the exact same point in time. However, they are both adjusted for age to correct for this. Lastly, our findings should be generalised with caution. The cohort of Generation $\mathrm{R}$ had some drop-out over the years, resulting in a relatively healthy sample [21]. Next to the drop-out, we only included children data on teacher-reported problems. The excluded children were more likely to use less care, have a non-Western background, have lower-educated parents, live in a one-parent family and have more mother-reported problems compared to the rest of the Generation R sample. However, it is not likely that this selection of participants altered our results [40]. In ALSPAC, a longitudinal study comparable to Generation R, drop-out led to an underestimation of problem prevalence, but the association between determinants and outcome were not altered [41]. The dropout did reduce the statistical power in the ALSPAC study, but we limited this effect by applying multiple imputation.

\section{Future research and implications}

Based on our study, we have some recommendations for future research. As we focussed on psychosocial care in general, we recommend focussing more on the specific types and duration of psychosocial care in future research. Associations might be different for preventive, basic/community and specialised care, as demonstrated in comparable studies on children's psychosocial care use [42, 43]. Furthermore, we recommend studying 
the predictive value of teacher-reported problems at multiple points in time. Problems reported closest to the care use show the strongest association, but problems earlier in life can contribute to early intervention strategies. Moreover, we recommend further research into the pathways teachers can support or provide for non-Western children towards psychosocial care. Pathways might be influenced by teacher characteristics such as the age, gender and ethnic background. Also awareness of available care, parenting support and services, personal experiences with mental health care and the attitude towards care might influence this pathway. Therefore, it is important to take these characteristics into account when exploring the pathways in future studies. Insight might reveal important further directions on how to improve access to psychosocial care for children with a non-Western background.

Our findings suggest that children who use care at 9 years old have relatively more problems at 6 years old, according to the teacher. Prevention strategies should focus on the teacher's unique position, especially since the association is independent of mother-reported problems. In fact, teachers might have an important role in the identification and access to care of children with a non-Western background [25], particularly given that their parents are less likely to report problems and refer their child to psychosocial care $[7,8,18]$.

\section{Conclusion}

Our findings indicate that teachers might have an important role, next to parents, in the identification of emotional and behavioural problems and children's access to psychosocial care. This may be particularly important for non-Western children, as they use less care than Western children, despite other research showing that they generally display higher levels of problems. Further research is warranted to improve our understanding of psychosocial care use by children with a Western and non-Western background.

Supplementary Information The online version contains supplementary material available at https://doi.org/10.1007/s00787-021-01937-w.

Acknowledgements The Generation R Study was conducted by Erasmus Medical Center in close collaboration with the School of Law and Faculty of Social Sciences of the Erasmus University Rotterdam, the city of Rotterdam, the Youth and Family Centre (CJG) Rijnmond and the Stichting Trombosedienst and Artsenlaboratorium Rijnmond, Rotterdam. We gratefully acknowledge the contribution of children and their parents, teachers, general practitioners, hospitals, midwives, and pharmacies in Rotterdam.

Funding The first phase of the Generation R Study is made possible by financial support from the Netherlands Organization for Health Research and Development (ZonMW, grant number 10.000.1003). This particular study is made possible by funding of the city of Rotterdam.
Availability of data and material See the Generation $\mathrm{R}$ design paper [21]. Data is available when collaboration is established.

Code availability Not applicable.

\section{Declarations}

Conflict of interest The authors declare no conflict of interest.

Ethical approval The Medical Ethics Review Board of the Erasmus Medical Center approved the study protocols. Therefore the study has been performed in accordance with the ethical standards laid down in the 1964 Declaration of Helsinki and its later amendments. All parents provided written informed consent prior to their inclusion and before the start of each phase in the Generation R Study.

Open Access This article is licensed under a Creative Commons Attribution 4.0 International License, which permits use, sharing, adaptation, distribution and reproduction in any medium or format, as long as you give appropriate credit to the original author(s) and the source, provide a link to the Creative Commons licence, and indicate if changes were made. The images or other third party material in this article are included in the article's Creative Commons licence, unless indicated otherwise in a credit line to the material. If material is not included in the article's Creative Commons licence and your intended use is not permitted by statutory regulation or exceeds the permitted use, you will need to obtain permission directly from the copyright holder. To view a copy of this licence, visit http://creativecommons.org/licenses/by/4.0/.

\section{References}

1. Gritti A, Bravaccio C, Signoriello S, Salerno F, Pisano S, Catone G, Gallo C, Pascotto A (2014) Epidemiological study on behavioural and emotional problems in developmental age: prevalence in a sample of Italian children, based on parent and teacher reports. Ital J Pediatr 40:19

2. Merikangas KR, He J, Brody D, Fisher P, Bourdon K, Koretz D (2010) Prevalence and treatment of mental disorders among US children in the 2001-2004 NHANES. Pediatrics 125:75-81

3. Ravens-Sieberer U, Wille N, Erhart M, Bettge S, Wittchen H-U, Rothenberger A, Herpertz-Dahlmann B, Resch F, Hölling H, Bullinger M (2008) Prevalence of mental health problems among children and adolescents in Germany: results of the BELLA study within the National Health Interview and Examination Survey. Eur Child Adolesc Psychiatry 17:22-33

4. Zwirs BWC, Burger H, Schulpen TWJ, Wiznitzer M, Fedder H, Buitelaar JK (2007) Prevalence of psychiatric disorders among children of different ethnic origin. J Abnorm Child Psychol 35:556-566

5. Georgiades K, Duncan L, Wang L, Comeau J, Boyle MH and Ontario Child Health Study T (2019) Six-month prevalence of mental disorders and service contacts among children and youth in Ontario: evidence from the 2014 Ontario Child Health Study. The Can J Psychiatry 64:246-255

6. Mock-Muñoz de Luna CJ, Vitus K, Torslev MK, Krasnik A, Jervelund SS (2019) Ethnic inequalities in child and adolescent health in the Scandinavian welfare states: the role of parental socioeconomic status-a systematic review. Scand J Public Health 47:679-689

7. Bevaart F, Mieloo CL, Wierdsma A, Donker MCH, Jansen W, Raat H, Verhulst FC, van Oort FVA (2014) Ethnicity, 
socioeconomic position and severity of problems as predictors of mental health care use in 5-to 8-year-old children with problem behaviour. Soc Psychiatry Psychiatr Epidemiol 49:733-742

8. De Haan AM, Boon AE, Vermeiren RRJM, De Jong JT (2012) Ethnic differences in utilization of youth mental health care. Ethn Health 17:105-110

9. Erath SA, Keiley MK, Pettit GS, Lansford JE, Dodge KA, Bates JE (2009) Behavioral predictors of mental health service utilization in childhood through adolescence. J Dev Behav Pediatr 30:481

10. Ryan SM, Jorm AF, Toumbourou JW, Lubman DI (2015) Parent and family factors associated with service use by young people with mental health problems: a systematic review. Early Interv Psychiatry 9:433-446

11. Villatoro AP, Mays VM, Ponce NA, Aneshensel CS (2018) Perceived need for mental health care: The intersection of race, ethnicity, gender, and socioeconomic status. Soc Mental Health 8:1-24

12. Verhulp EE, Stevens GWJM, Van de Schoot R, Vollebergh WAM (2013) Understanding ethnic differences in mental health service use for adolescents' internalizing problems: the role of emotional problem identification. Eur Child Adolesc Psychiatry 22:413-421

13. Sayal K (2006) Annotation: pathways to care for children with mental health problems. J Child Psychol Psychiatry 47:649-659

14. Brown JD, Wissow LS, Gadomski A, Zachary C, Bartlett E, Horn I (2006) Parent and teacher mental health ratings of children using primary-care services: interrater agreement and implications for mental health screening. Ambul Pediatr 6:347-351

15. Loades ME, Mastroyannopoulou K (2010) Teachers' recognition of children's mental health problems. Child Adolesc Mental Health 15:150-156

16. Raven D, Jörg F, Visser E, Schoevers RA and Oldehinkel AJ (2018) Predicting initial specialist mental health care use in adolescence using self-, parent-, and teacher-reported problem behavior: a prospective community-based record-linkage study. J Clin Psychiatry 79:4. https://doi.org/10.4088/jcp.17m11484

17. Sourander A, Helstelä L, Ristkari T, Ikäheimo K, Helenius H, Piha J (2001) Child and adolescent mental health service use in Finland. Soc Psychiatry Psychiatr Epidemiol 36:294-298

18. Eijgermans DGM, Raat H, Jansen PW, van de Looij-Jansen PM, Hillegers MHJ and Jansen W (2021) Children's use of psychosocial care in a population-based longitudinal study: less likely for girls, children with a non-Western background and children with a high quality of life. Eur Child Adolesc Psychiatry. https://doi.org/10. 1007/s00787-021-01737-2

19. Gudiño OG, Lau AS, Yeh M, McCabe KM, Hough RL (2009) Understanding racial/ethnic disparities in youth mental health services: do disparities vary by problem type? J Emot Behav Disord $17: 3-16$

20. Rosen A, Byrne P, Goldstone S, McGorry P (2015) Early intervention for better mental health services. Psychiatry 1:1990-2010

21. Kooijman MN, Kruithof CJ, van Duijn CM, Duijts L, Franco OH, van Ijzendoorn $\mathrm{MH}$, de Jongste JC, Klaver CCW, van der Lugt A, Mackenbach JP (2016) The generation R study: design and cohort update 2017. Eur J Epidemiol 31:1243-1264

22. Achenbach TM, Rescorla LA (2000) Reliability, cross-informant agreement, and stability. Manual for the ASEBA preschool forms and profiles. University of Vermont, Research center for children, youth, \& families, Burlington, VT, pp 74-100

23. Statistics Netherlands (2004) Immigrants in the Netherlands 2004 (Allochtonen in Nederland 2004). Statistics Netherlands, Voorburg/ Heerlen

24. Achenbach TM, Rescorla LA (2001) Manual for the ASEBA school-age forms \& profiles. University of Vermont. Research Center for Children, Youth, \& Families, Burlington, VT

25. Ivert A-K, Svensson R, Adler H, Levander S, Rydelius P-A, Levander MT (2011) Pathways to child and adolescent psychiatric clinics: a multilevel study of the significance of ethnicity and neighbourhood social characteristics on source of referral. Child Adolesc Psychiatry Ment Health 5:1-12

26. Kamperman AM, Komproe IH, De Jong JTVM (2007) Migrant mental health: a model for indicators of mental health and health care consumption. Health Psychol 26:96

27. Fassaert T, Hesselink AE, Verhoeff AP (2009) Acculturation and use of health care services by Turkish and Moroccan migrants: a crosssectional population-based study. BMC Public Health 9:1-9

28. Nap A, van Loon A, Peen J, van Schaik DJF, Beekman ATF, Dekker JJM (2015) The influence of acculturation on mental health and specialized mental healthcare for non-western migrants. Int J Soc Psychiatry 61:530-538

29. Lê Cook B, Brown JD, Loder S, Wissow L (2014) Acculturation differences in communicating information about child mental health between Latino parents and primary care providers. J Immigr Minor Health 16:1093-1102

30. Nanninga M, Reijneveld SA, Knorth EJ, Jansen DE (2016) Expectations of barriers to psychosocial care: views of parents and adolescents in the community. Eur Child Adolesc Psychiatry 25:107-117

31. Flink IJE, Beirens TMJ, Butte D, Raat H (2014) Help-seeking behaviour for internalizing problems: perceptions of adolescent girls from different ethnic backgrounds. Ethn Health 19:160-177

32. Schnyder N, Panczak R, Groth N, Schultze-Lutter F (2017) Association between mental health-related stigma and active help-seeking: systematic review and meta-analysis. Br J Psychiatry 210:261-268

33. Johnson MH, McNeish R and Vargo AC (2020) Exploring ethnic differences in caregiver perceptions of the quality of children's mental health care. J Child Fam Stud 29:2552-2567.

34. Statistics Netherlands (2019) Jongeren met jeugdhulp (in \% van alle jongeren tot 18 jaar). Statistics Netherland, Rotterdam

35. Mathews F, Newlove-Delgado T, Finning K, Boyle C, Hayes R, Johnston P and Ford T (2020) Teachers' concerns about pupil's mental health in a cross-sectional survey of a population sample of British schoolchildren. Child Adolesc Mental Health 26:99-105

36. Beyer T, Postert C, Müller JM, Furniss T (2012) Prognosis and continuity of child mental health problems from preschool to primary school: results of a four-year longitudinal study. Child Psychiatry Hum Dev 43:533-543

37. Jörg F, Visser E, Ormel J, Reijneveld SA, Hartman CA, Oldehinkel AJ (2016) Mental health care use in adolescents with and without mental disorders. Eur Child Adolesc Psychiatry 25:501-508

38. Zwaanswijk M, Verhaak PFM, Bensing JM, Van der Ende J, Verhulst FC (2003) Help seeking for emotional and behavioural problems in children and adolescents: a review of recent literature. Eur Child Adolesc Psychiatry 12:153-161

39. O'Brennan LM, Bradshaw CP, Furlong MJ (2014) Influence of classroom and school climate on teacher perceptions of student problem behavior. Sch Ment Heal 6:125-136

40. Gustavson K, von Soest T, Karevold E, Røysamb E (2012) Attrition and generalizability in longitudinal studies: findings from a 15 -year population-based study and a Monte Carlo simulation study. BMC Public Health 12:1-11

41. Wolke D, Waylen A, Samara M, Steer C, Goodman R, Ford T, Lamberts K (2009) Selective drop-out in longitudinal studies and nonbiased prediction of behaviour disorders. Br J Psychiatry 195:249-256

42. Hacker KA, Penfold RB, Arsenault LN, Zhang F, Soumerai SB, Wissow LS (2017) The impact of the massachusetts behavioral health child screening policy on service utilization. Psychiatr Serv 68:25-32

43. Brattfell ML, Jozefiak T and Wichstrøm L (2020) Predictors of community versus specialty mental health service use: a prospective cohort study. Eur Child Adolesc Psychiatry 30:953-960 